\title{
Sustainability using cover crops in Mediterranean tree crops, olives and vines - Challenges and current knowledge
}

\author{
José A. GÓMEZ1
}

\begin{abstract}
Tree crops cover a large area of European landscape, 13.3 million hectares, with olive, grapes, nuts and almonds been the most extended and mostly concentrated in Mediterranean areas. The cultivation of tree crops in rain limited Mediterranean areas depend on an adequate management of water balance that, been historically mostly based on bare soil, has created severe erosion and offsite contamination problems. Temporary cover crops can be an alternative to control these problems with a larger effect on erosion control than on reducing runoff, and a moderate impact on soil properties. This impact depend strongly on the ability to implement temporary cover crops that achieve a significant development during the rainy season while simultaneously minimizing the competition for soil water with the major crop, which is not always easy in commercial farms. This balance between soil protection and yield has been achieved in some conditions but not in others, and a significant reduction in yield has been reported for some situations. This potential risk of yield decrease, combine with the difficulty to see a collapse in yield due to soil degradation by water erosion in the short/ medium term can explain, partially, the reluctance of farmers for an extensive use of temporary cover crops. The development of improved strategies for using temporary cover crops which could include the use of water balance models, new varieties better adapted to the region, and strategies for restoring ground cover in severely degraded orchards seems to be necessary, coupled with regulations and incentive to their use by farmers. Future research should focus in the less understood elements of this system, among them root development, biomass production, phenology under different microclimate of the cover crops and the main tree crops, use of cover crops mixes, which are hampering the tuning of the system for specific conditions. It is also necessary a better definition and measurement of the impacts of cover crops on biodiversity that should be related to the landscape conditions.
\end{abstract}

Keywords: olive, vines, sustainability, water balance, erosion, Mediterranean

\section{Mediterranean tree crops}

Tree crops are a key element of the European agricultural landscape with more than 13 million hectares of permanent tree crops in the EU-28. The majority of them, approximately 80 per cent of the surface, are concentrated in areas with Mediterranean type of climate (Table 1). This is because the majority of these crops in the EU (such as olives, citrus or almonds) are best grown under a Mediterranean type of climate. The only exception among the dominant tree crops are vines. The 3.2 million hectares of vines in the EU-
28 are distributed across the continent among 21 countries, from Sweden to Malta, albeit the majority of them are also concentrated in Mediterranean areas.

The major reason for that distribution is the favourable conditions in terms of temperature and radiation. Other reasons are the rusticity of some of these tree crops, particularly olives and almonds, which allows cultivation in areas not suitable for other crops or grazing and their double role as a food and cash crop. However, the Mediterranean type of climate is characterized by a limited, and highly variable, precipitation in relation

\footnotetext{
${ }^{1}$ Institute for Sustainable Agriculture (IAS) CSIC. Avenida Menéndez Pidal S/N 14004. Cordoba, Spain. E-mail: joseagomez@ias.csic.es
} 


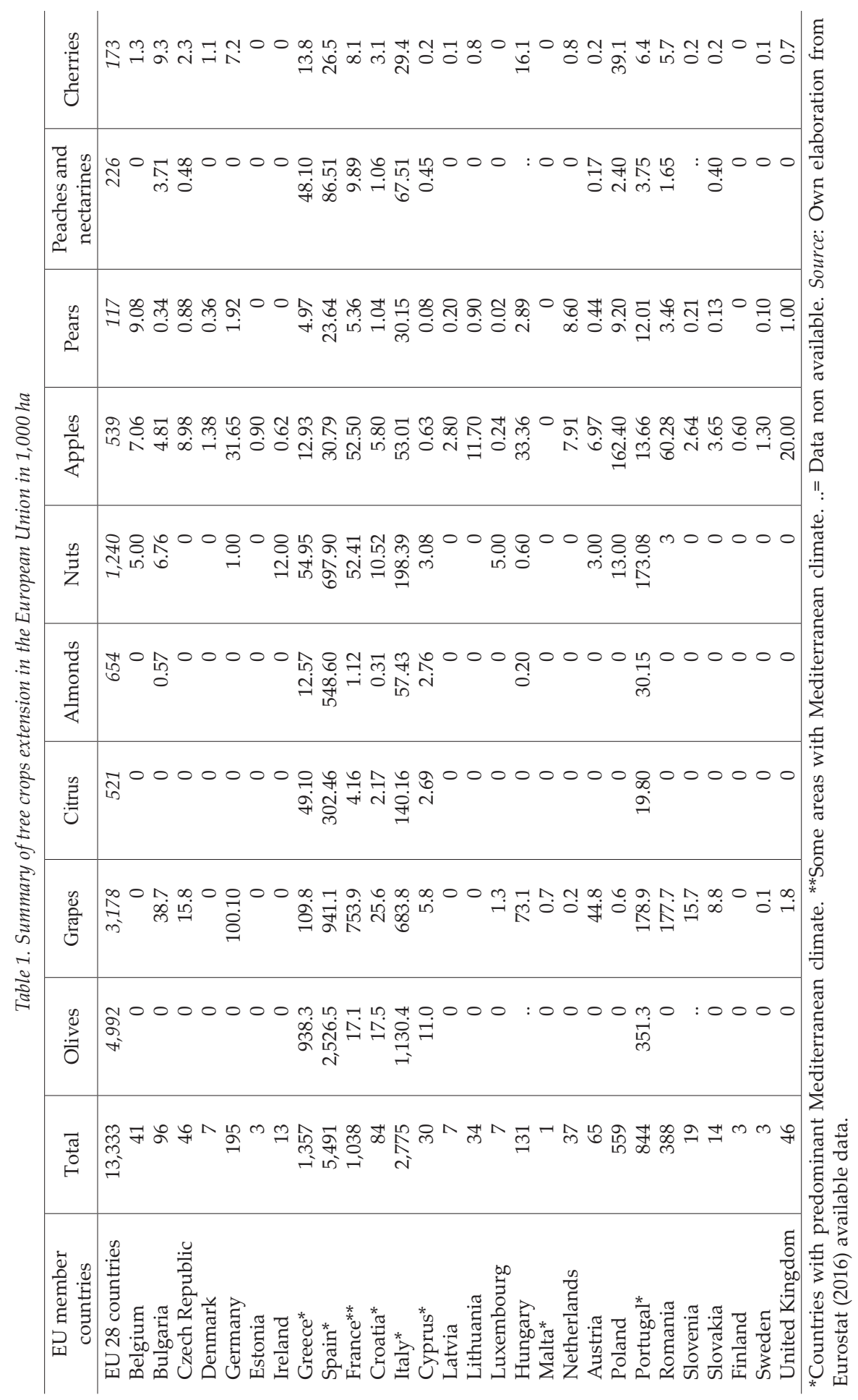


to the potential evapotranspiration (ETo) and by a dry season during the period of maximum temperature and ETo (Figure 1).

Agronomical practices in orchards in Mediterranean areas have evolved in the direction of prioritizing the improvement of soil water balance for the tree, to insure productivity and survival of trees and crops under limiting water conditions.

Historically this has been achieved combining three major elements. One is a low tree plant density, which allows a large soil volume for the roots to explore for soil water, with the other two been a limitation of the canopy size by pruning and elimination of weeds to prevent competition for soil water with the tree. This, agronomically sounded, strategy has been successful for allowing tree cultivation over centuries in Mediterranean areas, but it has also created landscapes, like the one shown in Photo 1 characterized by a simplified landscape with limited ground cover on sloping areas. This has resulted in some environmental problems, particularly severe in some areas of the Mediterranean. Several studies have noted these problems, particularly in olives growing areas (e.g. Beauffoy, G. 2001; Scheidel, A. and Krausmann, F. 2011). They can be summarized in: soil degradation by accelerated water erosion, decrease of water quality by offsite contamination, decrease of biodiversity and an increasing pressure on water

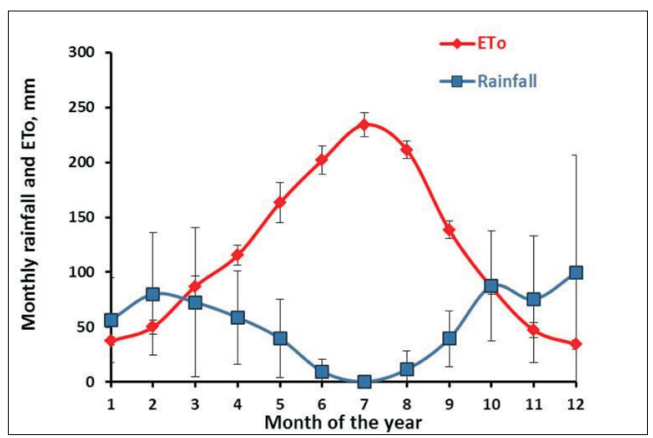

Fig. 1. Average monthly precipitation and potential evapotranspiration (ETo) for Cordoba, Southern Spain, from 2001 to 2015 . Error bars indicates standard deviation. resources in areas where irrigation, which is almost exclusively deficit irrigation, has expanded in recent decades.

In an effort to mitigate some of these problems it has been an continuous attempt for in introducing the use of cover crops in tree crops on Mediterranean areas, at least since 1969 (Ruíz de Castroviejo, J. 1969). It is worth clarifying that when talking about cover crops in the context of rainfed (or deficit irrigation) tree crops in Mediterranean conditions we always refer to temporary cover crops. Photo 2 summarized the concept of temporary cover crops which is based on seeding, or allowing growing, of herbaceous vegetation in the lanes during the rainfall season (autumn/fall and winter) controlling chemically or mechanically the cover crop in early spring to prevent losses of soil water by transpiration, and maintaining its residues over the surface until next fall when, ideally, it will regrow from seeds produced during the previous year.

This communication revises some of the issues regarding sustainable cultivation of tree crops in Mediterranean conditions with the use of cover crops, focusing particularly in olives and vines.

\section{Modification of soil properties, erosion and runoff losses at plot scale}

Most of the available information to evaluate the impact of the use of temporary cover crop as an alternative to bare soil comes from experiments at plot scale. Figure 2 summarizes results from experiments carried out under natural rainfall conditions in experiments lasting 2 or more years in plots at least $12 \mathrm{~m}$ long. This criterion was followed to limit the bias induced by short term experiments, simulated rainfall, or those performed at very small scale not including relevant processes. Figure 2 (top side) shows how the use of cover crops has a clear and significant effect on reducing soil losses in olive orchards and vineyards at plot scale. In all the experiments this reduction was found, with an average reduction close to 60 per cent. 


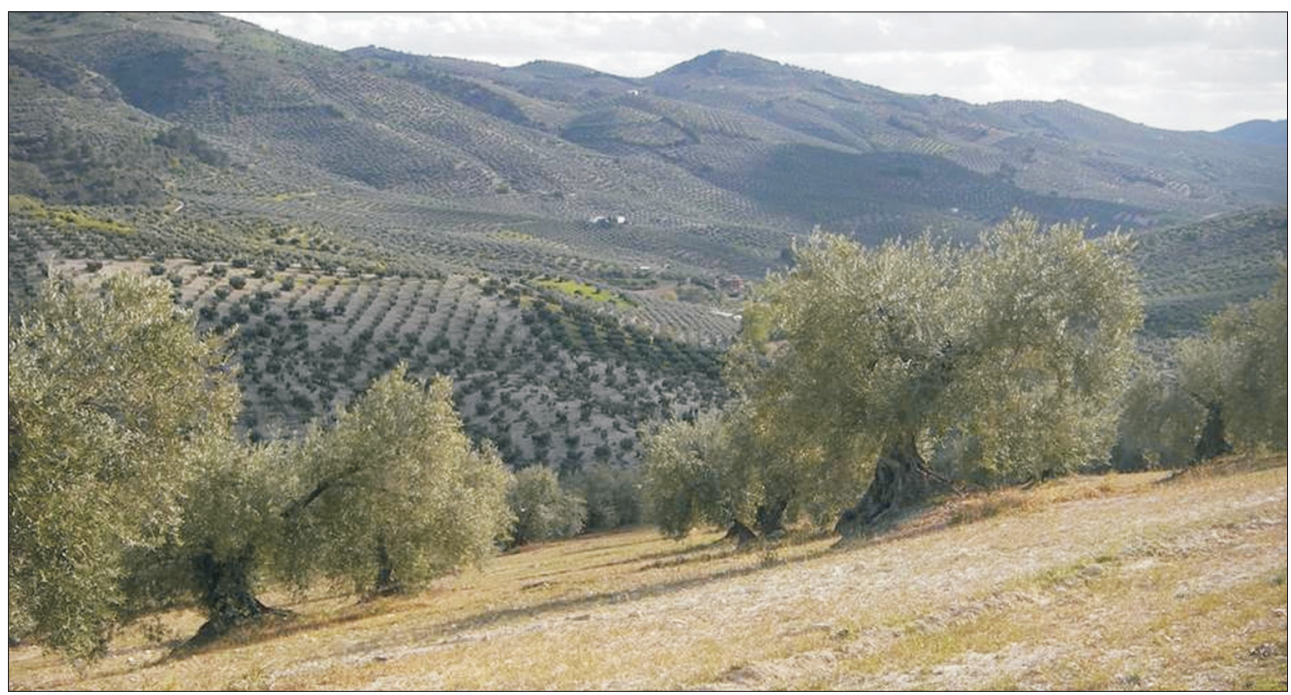

Photo 1. View of olive cultivation in a mountainous area in Southern Spain (Montefrío).

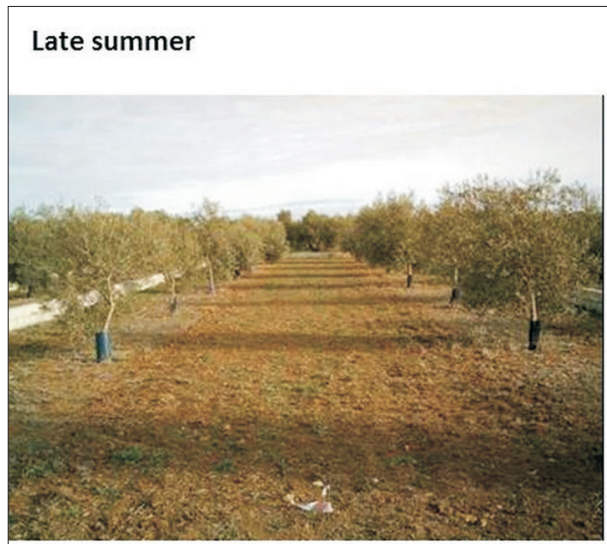

Fall

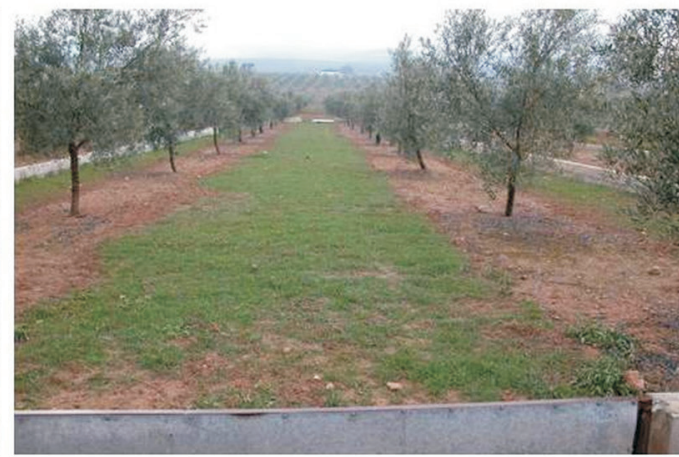

Spring

Winter
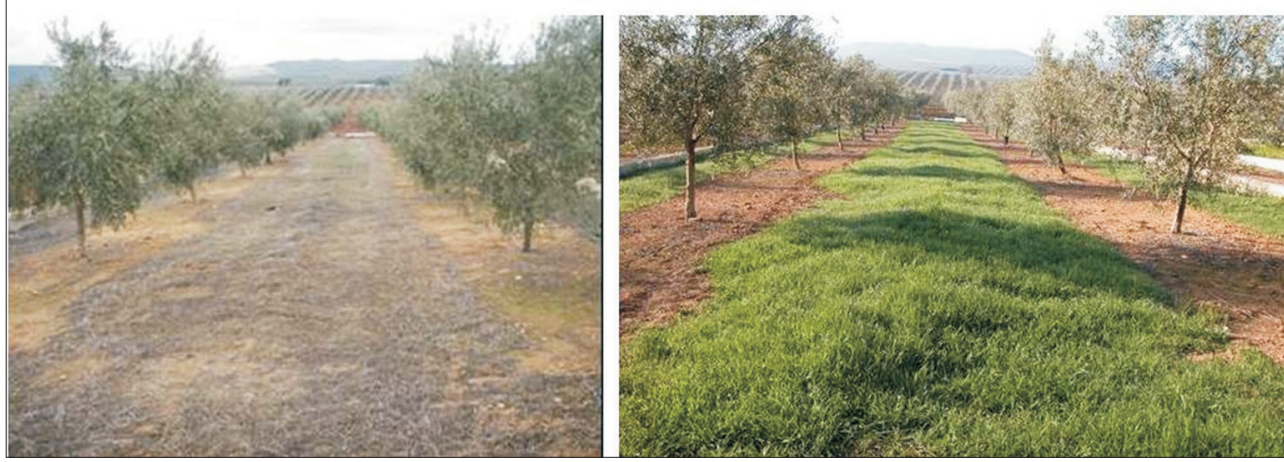

Photo 2. Evolution of a temporary cover crop in an olive orchard during the four seasons of the year. 
The effect on average annual runoff is shown in Figure 2 (down side). In this case the effect of the use of cover crops is not as clear and although there is an overall reduction in average annual runoff of approximately 25 per cent, this reduction is site specific with some orchards and vineyard presenting very small reductions in cover crops (CC) compared to bare soil by conventional tillage (CT) or no tillage with bare soil with herbicide (NT) or even slight increase in runoff, with others showing a large reductions. The reasons for that different answer in runoff and soil losses have been discussed in detail elsewhere (e.g. Gómez, J.A. et al. 2011).

They can be summarized in that while the reduction in soil losses is primarily the result of physical protection by the cover crop and its residues, the mechanism controlling infiltration is more complex and varied with
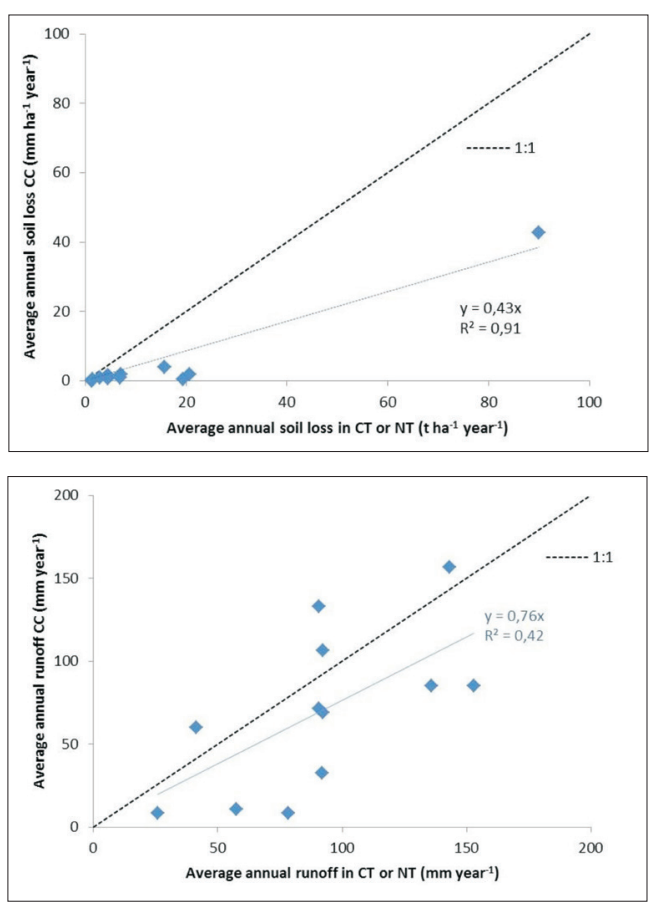

Fig. 2. Comparison of average annual runoff losses (top) and soil losses (down) between cover crops (CC) and bare soil management by tillage (CT) or herbicide (NT) in olives and vineyards. Source: Own elaboration from data in Biddoccu, M. et al. 2016, and Gómez, J.A. et al. 2009a, 2011. sites. In situations where infiltration is limited by surface sealing or reduced porosity of the top soil the over crop has a clear effect, however in situations while the infiltration rate is controlled by saturation of the soil profile or by subsurface layers the effect of the cover crops is very small or negligible.

In Mediterranean areas it is frequent to have orchards and vineyards on shallow soils and also periods of high precipitation in which the soil profile is close to saturation. It reasonable to expect that this different answer in runoff and soil losses when using cover crops can be a widespread phenomenon in Mediterranean tree crops. It is worth noting that MAETENs, W. et al. (2012) in a metanalysis of plot experiments in Europe also detected a higher effect of conservation tillage in reducing soil losses compared runoff losses when compared to conventional systems. Figure 3 shows for two long term experiments in vineyards and olives the annual variability of the reduction in runoff and soil losses. It is apparent the same overall trend commented before and also that this variability must be related to the interaction between rainfall, soil conditions and soil management within each year, since the overall correlation with annual rainfall is weak.

The spatial distribution of soil properties within an orchards or vineyard is different to those in a field crop, since it has a mosaic pattern in which the influence of the tree and the cover crop induces differences in some of them, like infiltration rate or bulk density. When interpreting and modelling hydrological processes, such as runoff generation, water balance or water erosion, this heterogeneity depicted in photos needs to be considered (Photo $3 a$ and $3 b$ ). For instance, CAstro, G. et al. (2006) showed the relevance of run-on in the under canopy and cover crop area with some of the runoff generated in the area of the lane with bare soil These effects have been, sometimes, incorporated into the efforts for modelling runoff and water erosion in olives and vineyards at hillslope scale. For instance, Romero, P. et al. (2007) developed and validated values for the $\mathrm{CN}$ method for different soil 

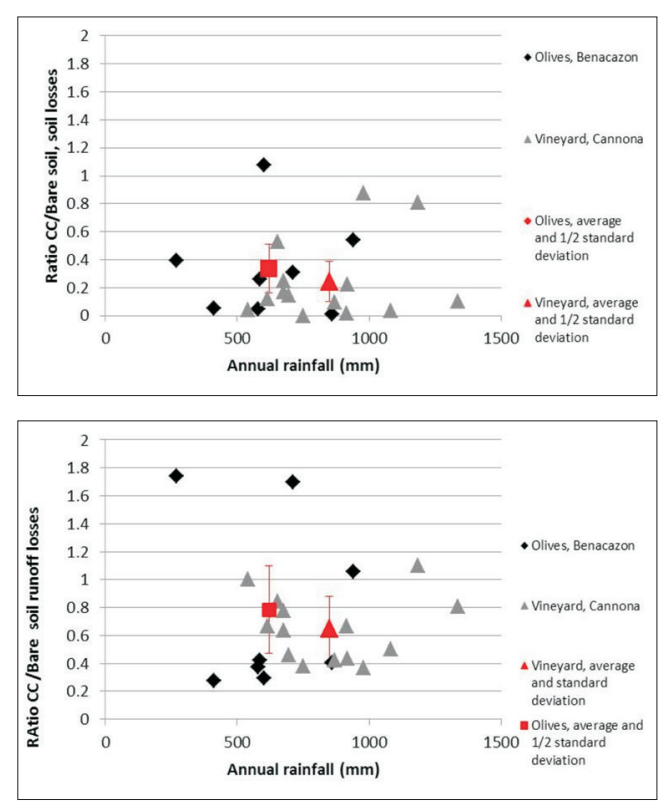

Fig. 3. Annual ratio of soil (top) and runoff losses (down) between cover crops (CC) and bare soil management by tillage (CT) or herbicide (NT) in olives and vineyards. Source: Own elaboration from data in Biddoccu, M. et al. (2016), and Gómez, J.A. et al. (2011) and unpublished data.

management in olive orchards, and these $\mathrm{CN}$ values have been used successfully in water balance models in olives (АвAZI, U. et al. 2012).

The CN method has also been used for determining runoff losses in water balance modes in vines in Mediterranean conditions (e.g. Celette, F. et al. 2010) although in these case the $\mathrm{CN}$ values were apparently taken from the values developed for orchards in USA by the USDA. The effect of soil management in water erosion in olives and vines has been incorporated in RUSLE through calibration of $C$ values for specific conditions. Gómez, J.A. et al. (2003) proposed several C values for different olive plant density and soil management in orchards considering the influence of the variation of soil moisture content during the year.

These $C$ values seem to provide reliable predictions of soil losses when compared to long term erosion rates estimations (VANWALLEGEM, T. et al. 2011) or plot data (MARIN, V.J. 2013).
Auerswald, K. and Schwab, A. (1999) proposed $C$ values for USLE for different soil management and vine plant density in Germany, although to our knowledge, these values have not been validated. When comparing $C$ values for vines proposed by different authors in Europe (Gómez, J.A. et al. 2016) it is noticeable that they show large differences even for apparently similar managements. This is probably for a combination of differences in the conditions for which they have been determined and the lack of a standard approach for its calibration and validation. Overall, all the $C$ values proposed for olives and vines capture the trend towards reduced erosion with the use of cover crops, albeit there is the need for extensive validation to evaluate the uncertainty existing on the predicted values of soil loss.

The modification of soil properties induced by the cover crop in an orchard and vine tend to be limited to the area where the cover crop is implanted, usually only a fraction of the orchard (see Photo 3-4), and tend to be concentrated in the top 0-20 $\mathrm{cm}$ of the soil (see GómEz, J.A. et al. 2009a). For this reason their overall impact on nutrient and carbon content in the orchards and vines, albeit significant, tend to be limited and related to the spatial extension of the cover crop strip. An element of major concern when extrapolating the benefits of the cover crops, in term of runoff and soil loss reduction, from experimental areas to commercial farms should be the large variability in the "quality" of the cover crop found in different farms (Photo 5-6). This "quality" should be understood as the ability to provide enough ground cover and biomass during the rainy season in a significant area of the orchard. In transects within a relatively small areas GómEz, J.A. et al. (unpublished data) measured in spring (before killing the cover crop) values of aboveground biomass for the cover crop area from $0.1 \mathrm{t} /$ ha (almost bare soil) to $1.8 \mathrm{t} / \mathrm{ha}$ (which provided a good ground cover).

There are several reasons for this large disparity in cover crops development, among them differences in soil quality, seed bank and soil management among different orchards. 

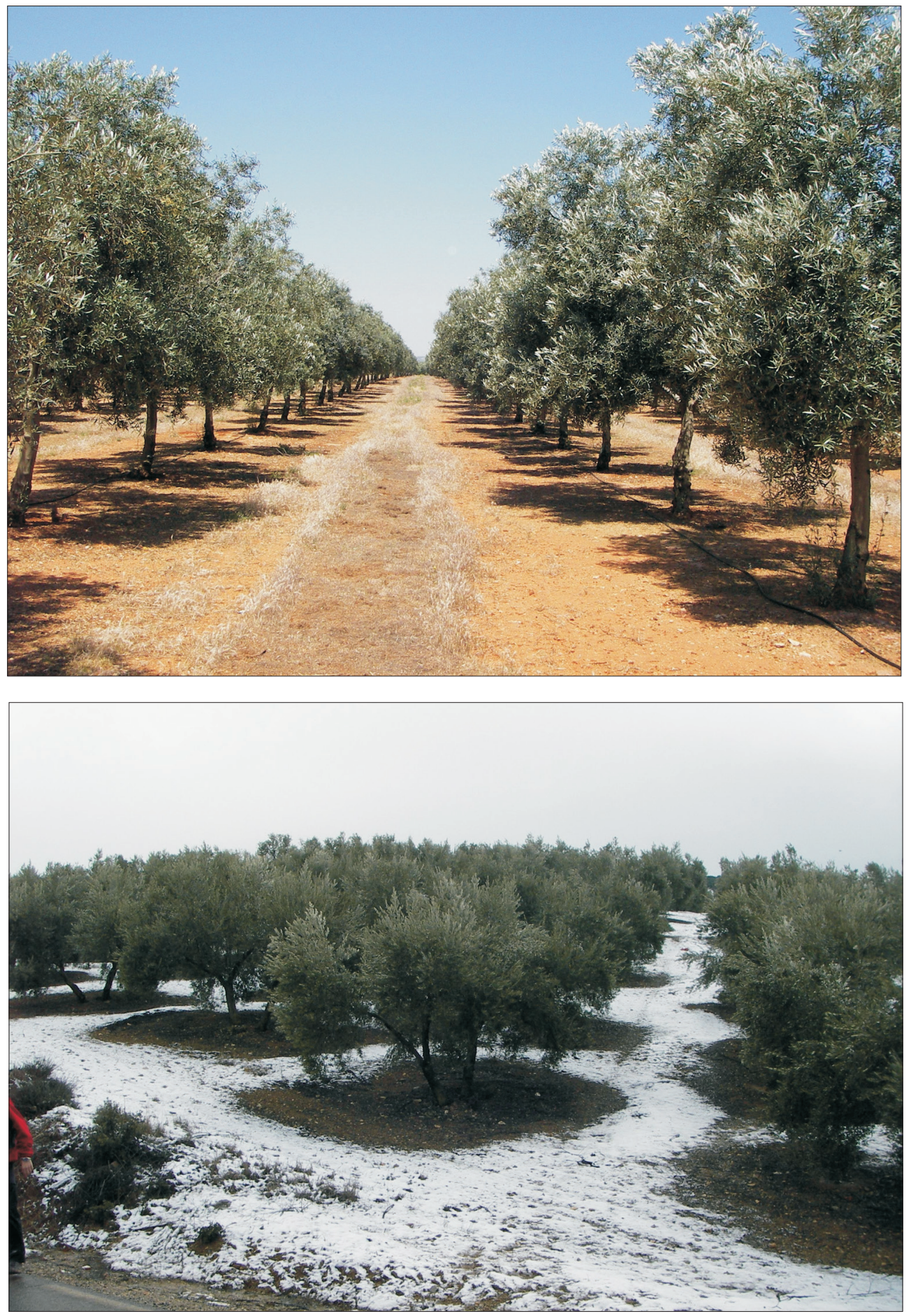

Photo 3-4. View of orchards showing the area of influence of the olive canopy (top) and the cover crop (down). 

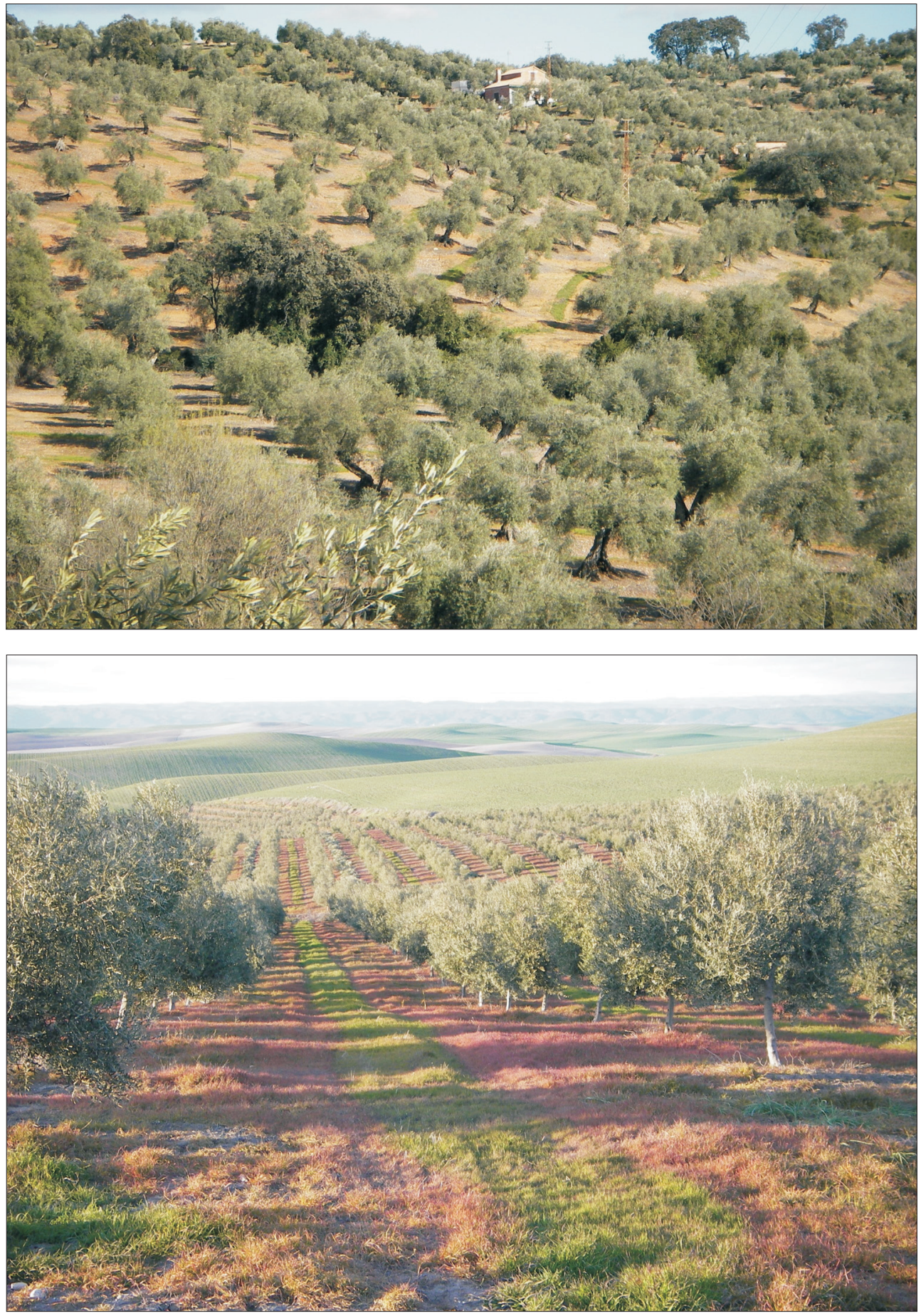

Photo 5-6. Comparison of two olive orchards declaring use of cover crops, Note narrow over crop strips in the upper picture compared to the one below. 
Similar differences in cover crop biomass production in the lanes of olive orchards have also been noted by other authors (e.g. Vicente-Vicente, J.L. 2017). These results highlight the need of more focused efforts in developing innovative strategies for achieving successful implementation of temporary cover crops in these situations which in many cases are associated to severely degraded soils. Gómez, J.A. et al. (2009b) noted this heterogeneity of cover crop conditions as one of the reasons for the large variability found in organic olive orchards with cover crop management. Gómez, J.A. et al. (2014a) discussed the implications of these large differences between experimental results and field situations when trying to estimate regional erosion rates for olive growing areas in Andalusia. He noted a variation of approximately 30 per cent in the predicted average erosion rate and severely degraded area estimation under current common agricultural policy (CAP) regulations regarding the compulsory use of cover crops when introducing a decrease in the efficiency of these cover crops based on calibrating the $C$ factor of RUSLE based on observations of cover crops status from field visits to several orchard in the region.

\section{Water balance and yield}

Water is the major limiting factor for agricultural production in semiarid environment with soil management playing a major role in controlling that water balance (HeNDERson, D.W. 1979). A modification of soil management such as the use of temporary cover crops in Mediterranean tree crop cannot be successful without understanding the implications for yield due to the modification of the water actually available to the crop. Figure 4 depicts the results of some experiments comparing the impact on olive fruit and wine yield of temporary cover crops in olives and wines. It is apparent that in some situations the system of temporary cover crops has been adjusted to provide soil pro- tection while achieving yields that are similar to those under bare soil management (e.g. CC controlled in early spring in Figure 4), although in other situations, (e.g. those controlled in mid-late spring in Figure 4) there is a significant decrease in yield.

This decrease when comparing those approaches (CC vs. CT) has been noted by other researchers in long-term experiments (e.g. Ferreira, I.Q. et al. 2013). This potential risk of a yield decrease remains a major obstacle for expanding the use of temporary cover crops in Mediterranean tree crops particularly under rainfed conditions. Another tool to fine tune the management of cover crops under a broad range of conditions is the use of simulation models to study its impact on water balance.

The literature describes several models developed for vines or olives. For instance, Celette, F. et al. (2011) presented WALIS as a simple model to simulate water partitioning in a crop association and use it to study the case of an intercropped vineyard, while AвAzI, U. et al. (2013) presented WABOL, other conceptual model for the case of intercropped olives. These studies concluded that the models provided realistic simulations, and they could be useful tools in providing a better understanding of cover crops in olives and vines. However, in both studies the authors mentioned the need for an extensive validation of the model results, which to date

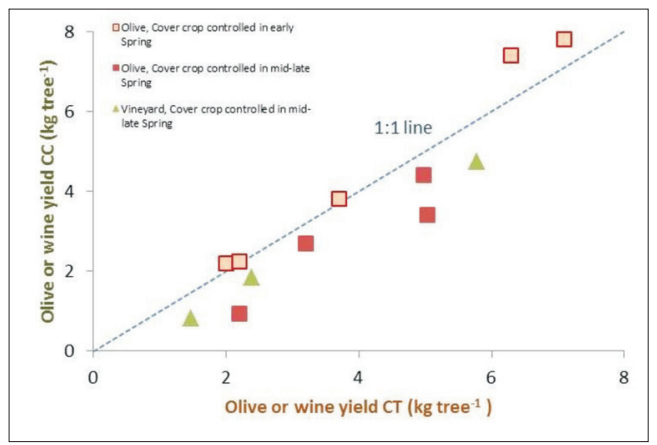

Fig. 4. Comparison of vine and olive yield in conventional tillage (CT) and temporary cover crop (CC). Source: Own elaboration from data in Gómez, J.A. 2005, and Ruíz-Colmenero, M. et al. 2011. 
still lacking. Parameterization of these models is of paramount importance and some of their key parameters still remain relatively poorly understood. Among those less understood are the phenology and root development of the tree crops and cover crops species under different conditions, the effect of capillary rise of subsurface layers during the dry season, and improved determination of the transpiration of the tree and cover crops in complex situation such as only partial ground cover or vertic soils are among the processes on which future research could be focused.

Even with the caveats mentioned by the authors, these conceptual models have provided insight into the feasibility of cover crop use under different conditions. Figure 5 summarizes the results of a study made by AвAzI, U. et al. (2012) in which the variations in olive transpiration under different conditions in cover crop and conventional tillage conditions were evaluated for Andalusia (Southern Spain). The model results predicted for some situations no significant differences in olive transpiration while it also predicted in other locations that CT seems to have slightly higher transpiration compared to CC, which agree with the agronomical experiments previously commented.

These conceptual models incorporate the effect of soil depth into soil water storage capacity, and so they have the potential to be used in the evaluation on the decrease of vine or olives potential productivity due to the

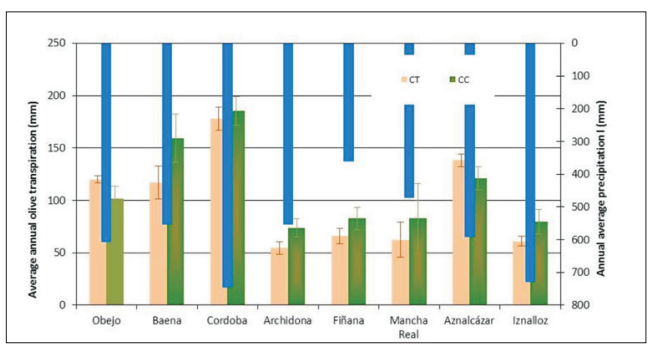

Fig. 5. Predicted olive transpiration for the average conditions rainfed olives in eight locations in Andalusia under conventional tillage (CT) and temporary cover crop (CC) for period 2006-2010. Error bars are standard deviation. Source: Adapted from AвAzi, U. et al. 2012. reduction of soil water availability accompanying the decrease of available soil depth by accelerated erosion. Gómez, J.A. et al. (2014a) evaluate the effect of decreasing soil depth on olive potential productivity under two contrasting situations both characteristic of large areas in the Mediterranean: soils with relatively good water holding capacity and stony soils with worse water holding capacity.

Figure 6 summarizes some of the major results of this study. One is that for soils with relatively deep rooting zones and good soil water holding capacity the decrease in potential yield appears clearly only at very shallow soil depths (see lines for Cordoba situation in Figure 6). The other is that the slope of the decrease in potential yield with decreasing soil depth is not very steep, so the year to year decrease in potential year can be masked by other factors such as climate variability, pest and effect of agronomical practices.

Both facts combined can help to understand, at least partially, the low priority given by farmers to the implementation of soil erosion control practices in olives. Basically, because the effects of soil degradation in the reduction of potential yield are difficult to be observed in the short or medium term, and its worst effects will be suffered in the future. VANWALleghem, T. et al. (2011) noted this situation in an mountainous olive growing area in Southern Spain in which the loss of ap-

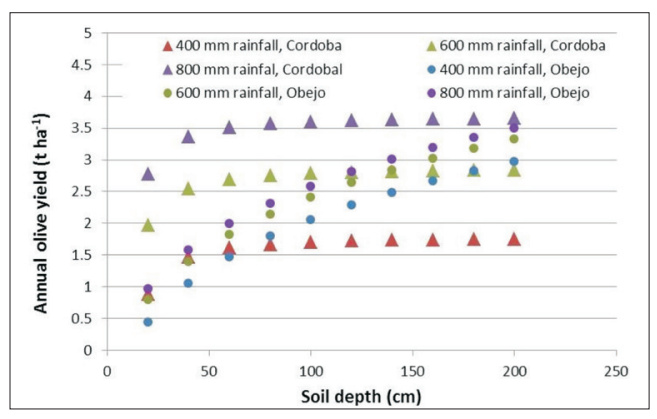

Fig. 6. Potential olive tree yield for different average annual rainfall and rooting depth for two contrasting situations: Obejo, sandy soils with coarse material and moderate water holding capacity; Cordoba, fine textured soils with high water holding capacity. Source: Adapted from data in Gómez, J.A. et al. 2014a. 
proximately $40 \mathrm{~cm}$ of rooting depth (from 120 to $80 \mathrm{~cm}$ approximately) in olive orchards in the area in the time span of two centuries was accompanied by an increase in yield, attributed to improved agronomical practices.

This situation, soil degradation due to soil erosion which is not currently decreasing yields dramatically and it will not do it in the medium term, can be a recurrent pattern in some of the tree crops growing areas in Mediterranean regions. All these facts considered suggest the need for regulations and incentives for erosion control on tree crops growing areas in the Mediterranean regions, particularly when most of the cost of erosion from these areas has been played downstream. Costs of soil erosion from agricultural areas in Europe has been estimated by MonTANARELLA, L. (2007) as an average of 48 EUR/ha per year (within the range from 4.8 to $93.0 \mathrm{EUR} / \mathrm{ha}$ per year) with off-site damages representing more than 90 per cent of this costs.

\section{A review of possible strategies for implementation cover crops}

Table 2 summarizes the major kind of cover crops alternatives and some of the main issues regarding the choice of the option best suited for a given objective, as well as some of the major features and decisions to be considered regarding their implantation and management. In the context of limited water availability the decision for temporary cover crops aimed mostly to soil management has oriented many of the experiences in olives and vines towards the use of grasses.

Several research projects has pursued the selection of grasses from local species which present a shorter growing cycle and could emerge with the first rains in fall and complete the seed development by late winter or early spring. This is the situation depicted in Photo 7 in which a difference in phenology of several weeks can be appreciated among several grasses. A shorter, best adapted, cycle will results in a lower risk for water competition but also in a better persistence of the

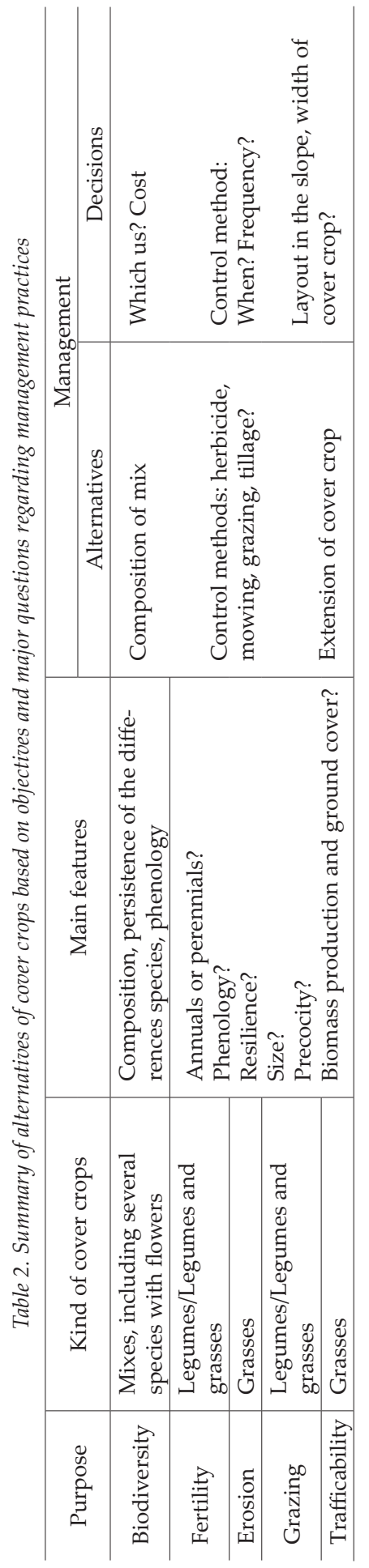




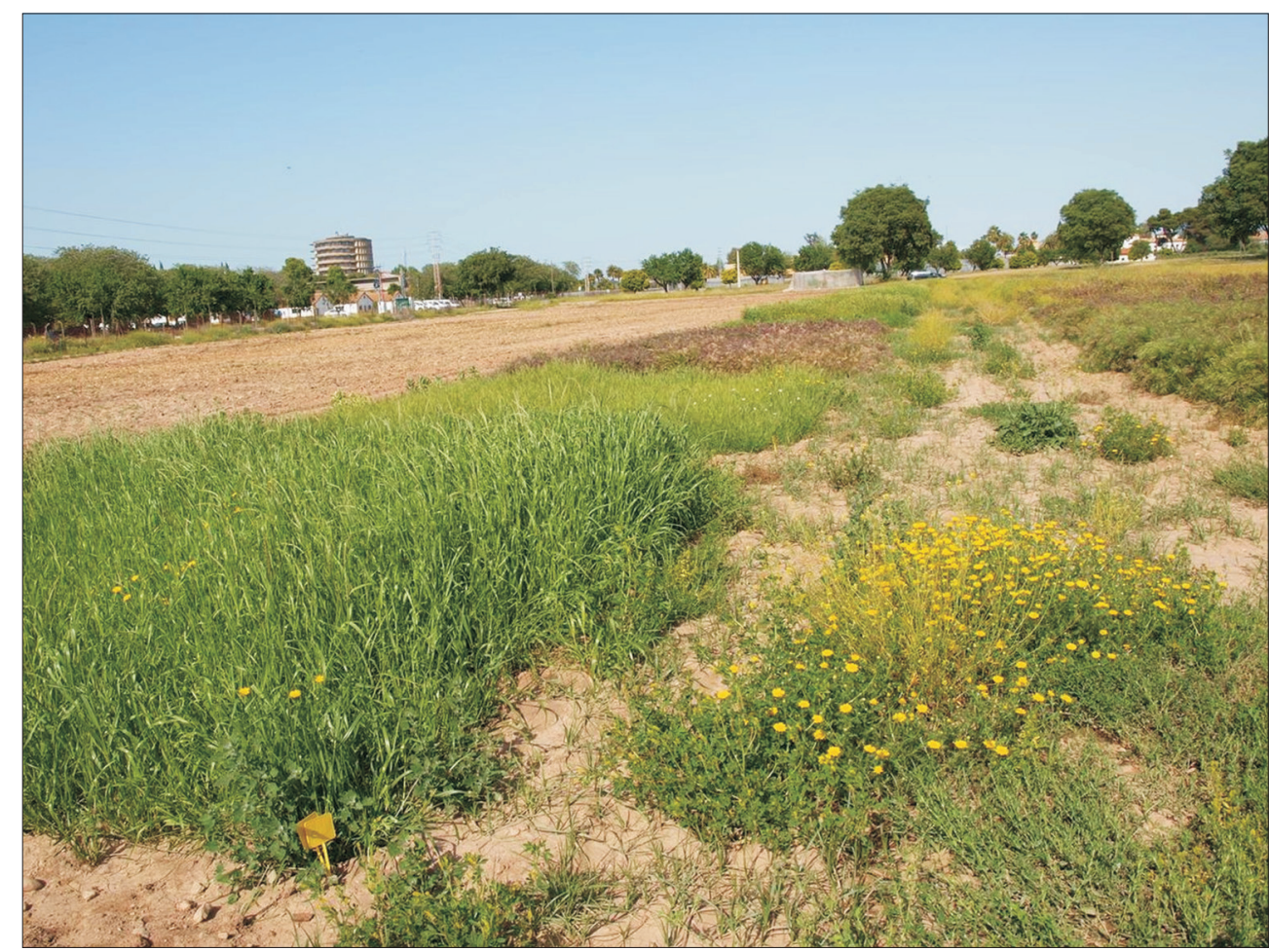

Photo 7. View of a cover crops experiment in Cordoba (Southern Spain) in early May. It is apparent the different in phenology between raygrass (front of picture still green) with Bromus (mid position in the picture, already eared and dried).

introduced cover crop in the plot, since it will have greater chances of producing seed before been controlled. In the search of better adapter species of grasses, precocity in emergence and a shorter size (an eventually lower biomass production) are also characters favoured. In vineyards, and lately although sporadically in olives, it is relatively frequent the use of mixes combining many species designed to increase biodiversity providing a large period with flowers in the orchard (e.g. SwEet, R.M, et al. 2010; GómEz, J.A. et al. 2014b).

There is a limited understanding of the dynamic of these mixes composed by a large number of different species. Gómez, J.A. et al. (2017) noted how a large number of them were not found in surveys in the seeded plots one and two years after their seeding, indicating how a lower number of species composed the majority of the flora in the plots. A better understanding the dynamic of mixes, in terms not only of composition and long term evolution but also in terms or air and root biomass production of the different components are necessary if we want to evaluate these promising new alternatives using water balance models. The use of less diverse mixes can be useful in this objectives, as well as in optimizing expenditure in seed of species that could actually been viable in a mix for a given condition. Figure 7 shows preliminary results of a study comparing the evaluation of a simple mix with three species chosen from local flora for their potential.

Despite all these efforts, statistics indicates that in many situations farmers still choose not to seed but to develop a cover crop from the flora naturally present in the 


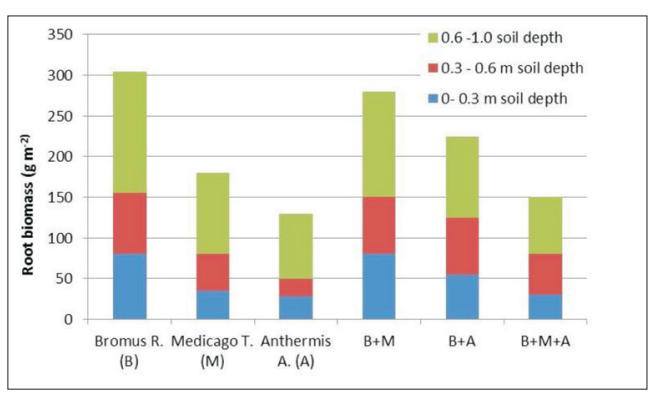

Fig 7. Distribution of root biomass with depth for different cover crops alternatives. Source: Adapted from SORIANo, M.A. et al. (2016).

orchard or vineyard. In Spain, for instance of the 30 per cent of the olive orchards using some kind of cover crops, 97 per cent of them opted for natural weeds and only 3 per cent were seeded (MAGRAMA 2013). Cost is probably the major reason for this situation, although other reasons, such as the loose coupling between severe erosion and yield losses discussed above can also play a role. Within this context it might be appropriate to consider strategies for introducing cover crops that will require a very limited cost for farmers, for instance species that could be easily propagated by them. Also concentrating more studies in situations where the naturally present weeds cannot be an alternative, such as in extremely degraded soils with poor fertility and exhausted seed bank.

\section{Effects on biodiversity}

An improvement in biodiversity is one of the benefits frequently mentioned when recommending the use of cover crops in tree crops under Mediterranean conditions. However, for an issue which is extremely complex involving different orders of plants and animals and different scales the experimental data are relative limited and indicate less conclusive results than when compared to other of the questions commented in this article.

For instance, BeAufoy, G. (2008) evaluating the results of a project evaluating the future of olive production in sloping land in sev- eral EU countries noted how the evaluation of the impact on biodiversity was extremely superficial, indicating the need for a more focused research. In the last years more publications have been published on the subject indicating the need for establishing a clear link between the biodiversity indicator measured and the landscape conditions where the study was performed. Paredes, D. et al. (2015) presented the results of a metanalysis evaluating the effect of cover crops in olive orchards in reducing the effect of several pests in Andalusia (Southern Spain), expected due to the increase of natural predators for these pests when using cover crops. Their results show that the presence or not of cover crops explained a very small part of the pest response, with local, landscape and regional variability explaining a large proportion of the variability in pest response variables.

This study points to perennial vegetation close to the focal crop as a promising alternative strategy for conservation biological control that should receive more attention. Focusing in a different indicator of biodiversity, songbirds, CAstro-CARo, J.C. et al. (2015) predicted that the presence of ground cover and landscape heterogeneity would have a positive effect on songbird communities, although the effect would be greatest in homogeneous environments.

The same team, however, in another study (CAstro-CAro, J.C. et al. 2014) measured a different response in the abundance and richness of omnivorous vs insectivorous birds to the use of cover crops depending on the presence or not of hedgerows. In their study, they indicated how the richness of insectivorous birds increased with the presence of cover crops, or hedgerow, in the olive orchards, with a maximum increase in richness when both elements (cover crops and hedgerows were present simultaneously). However, in the case of omnivorous birds they did not found a significant increase with any the presence of a cover crop, hedgerows, or both elements in the olive orchards compared to an orchard managed with a bare soil and not hedgerows. 
These examples illustrate the complexity of the relationship between use of cover crops and biodiversity. In this context it is not surprising that metanalysis evaluating the impact of cover crops on biodiversity in vineyards have found a moderate impact (WINTER, S. et al. 2016). However, despite this complexity many of the studies on biodiversity indicate that for a proper understanding of the effect of cover crops in Mediterranean tree crops they need to be linked to the landscape structure and, particularly, to the role of other vegetation in that landscape. The need for this link has been noted also in erosion studies. For instance, Gómez, J.A. et al. (2014c) in study in a small catchment on a vertic soil note the relevance of gully erosion which could explain the high erosion rates in very rainy years which had high runoff coefficients.

It is clear that much benefit could be achieved if some of the future studies evaluating the impact of cover crops could incorporate this across-scale effects and interaction with other vegetation for hydrological and biodiversity studies. Also for innovative approaches in the design of environmental regulations that link the benefits of the use of vegetation on landscape, biodiversity and erosion control on solid technical knowledge.

\section{Conclusion}

Soil protection, enhancement of biodiversity and water quality are three major ecosystem services that should be delivered by agricultural areas in addition to crop production. Tree crops cover a large area of the European landscape, particularly in the Mediterranean areas. Although research have demonstrated the potential of temporary cover crops to deliver those services in Mediterranean tree crops this potential is not fully exploited. The need to balance two conflicting objectives: an appropriate ground cover vs. an adequate management of the cover crop to limit its water consumption by transpiration to prevent yield reductions, results in many farm situations in a reduced ground cover and biomass production, which it is not enough to deliver those ecosystem services.

The conservative approach of many farmers to cover crops reflects also the limited understanding of key elements that are hampering the fine tuning of the system for specific farm conditions, which is a critical element for success. Future research should focus in the less understood elements of the tree and cover crops system such as: cover crops and tree root distribution and development; biomass production; phenology under different microclimate of the cover crops and the main tree crops; or performance of cover crops mixes. It is also necessary a better definition and measurement of the impacts of cover crops on biodiversity that should be related to the landscape conditions.

This research should lead to the development of improved strategies for using temporary cover crops which could include the use of water balance models, new varieties better adapted to the region, and strategies for restoring ground cover in severely degraded orchards. All they are necessary to expand the use of effective cover crops in Mediterranean tree crops by farmers, coupled with regulations and incentives to promote their use.

Acknowledgements: The contents of this article have been possible thanks to the contribution of different research projects. I would highlight specially the contribution of projects AGL2015-65036-C3-1 and Vinedivers (Spanish Ministry of Economy and Competitiveness), P12-AGR-931 (Andalusian Government) and FEDER funds which are currently funding research on this subject in the laboratory of Soil Erosion at IAS-CSIC.

\section{REFERENCES}

AbazI, U., Lorite, I. and Gómez, J.A. 2012. Impact of cover crops on soil conservation in olive orchards under different agroecological conditions combing a conceptual soil water balance model (WABOL) and RUSLE. Geophysical Research Abstracts 14. EGU2012-4174.

Abazi, U., Lorite, I.J., Cárceles, B., Martínez Raya, A., Durán, V.H., Francia, J.R. and Gómez, J.A. 2013. WABOL: A conceptual water balance model for analyzing rainfall water use in olive orchards under 
different soil and cover crop management strategies. Computers and Electronics in Agriculture 91. 35-48.

Auerswald, K. and Schwab, A. 1999. Erosion risk (C factor) of different viticultural practices. Viticultural and Enological Science 54. 54-60.

Beaufoy, G. 2001. EU Policies for Olive Farming. Unsustainable on all Counts. Brussels, BirdLife International-WWF.

Beaufoy, G. 2008. Reflections from an external evaluator on the future of olive production systems on sloping land. Journal of Environmental Management 89. 140-142.

Biddoccu, M., Ferraris, S., Opsi, F. and Cavallo, E. 2016. Long-term monitoring of soil management effects on runoff and soil erosion in sloping vineyards in Alto Monferrato (Northwest Italy). Soil \& Tillage Research 155. 176-189.

Castro, G., Romero, P., Gómez, J.A. and Fereres, E. 2006. Rainfall redistribution beneath an olive orchard. Agricultural Water Management 86. 249-258.

Castro-Caro, J., Gómez, J.A. and Sánchez, F.S. 2014. The role of cover crop and hedges in intensive olive orchards: Preventing soil erosion and promoting biodiversity. The Earth Living Skin. Soil, Life and Climate Changes EGU-SSS Conference, Bari, Italy.

Castro-Caro, J.C., Barrio, I.C. and Tortosa, F.S. 2015. Is the effect of farming practices on songbird communities landscape dependent? A case study of olive groves in southern Spain. Journal of Ornithology 155. 357-365.

Celette, F., Ripoche, A. and Gary, C. 2010. WALIS - A simple model to simulate water partitioning in a crop association: The example of an intercropped vineyard. Agricultural Water Management 97. 1749-1759.

EUROSTAT 2016. European Comission. http:// ec.europa.eu/eurostat/web/agriculture/statisticsillustrated Last accessed: 01.07.2016.

Ferreira, I.Q., Arrobas, M., Claro, A.M. and Rodrigues, M.A. 2013. Soil management in rainfed olive orchards may result in conflicting effects on olive production and soil fertility. Spanish Journal of Agricultural Research 11. 472-480.

Gómez, J.A. 2005. Effects of soil management on soil physical properties and infiltration in olive orchards - implications for yield. In Integrated soil and water management for orchard development. Role and importance. FAO Land and Water, Bulletin 10. Rome, FAO.

Gómez, J.A., Battany, M., Renschler, C.S. and Fereres, E. 2003. Evaluating the impact of soil management on soil loss in olive orchards. Soil Use Management 19. 127-134.

Gómez, J.A., Sobrinho, T.A., Giráldez, J.V. and Fereres, E. 2009a. Soil management effects on runoff, erosion and soil properties in an olive grove of Southern Spain. Soil and Tillage Research 102. 5-13.

Gómez, J.A., Álvarez, S. and Soriano, M.A. 2009b. Development of a soil degradation assessment tool for organic olive groves in Southern Spain. Catena 79. 9-17.

Gómez, J.A., Llewellyn, C., Basch, G., Sutton, P.B., Dyson, J.S. and Jones, C.A. 2011. The effects of cover crops and conventional tillage on soil and runoff loss in vineyards and olive groves in several Mediterranean countries. Soil Use and Management 27. 502-514.

Gómez, J.A., Infante-Amate, J., GonzÁlez de Molina, M., Vanwalleghem, T., Taguas, E.V. and Lorite, I. 2014a. Review: Olive Cultivation, its Impact on Soil Erosion and its Progression into Yield Impacts in Southern Spain in the Past as a Key to a Future of Increasing Climate Uncertainty. Agriculture 4. 170-200.

Gómez, J.A., Campos, M., Guzmán, G., CastilloLlangue, F. and Giráldez, J.V. 2014b. Use of heterogeneous cover crops in olive orchards to soil erosion control and enhancement of biodiversity. The Earth Living Skin. Bari, Soil, Life and Climate Changes EGU - SSS Conference.

Gómez, J.A., Vanwalleghem, T., De Hoces, A. and TAguAs, E.V. 2014c. Hydrological and erosive response of a small catchment under olive cultivation in a vertic soil during a five year period: Implications for sustainability. Agriculture, Ecosystems and Environment 68. 229-244.

Gómez, J.A., Biddoccu, M., Guzmán, G. and Cavallo, E. 2016. A simplified Excel tool for implementation of RUSLE2 in vineyards for stakeholders with limited dataset. Geophysical Research Abstracts 18. EGU2016-5142.

Gómez, J.A., Campos, M., Guzmán, G., CastilloLlangue, F., Vanwalleghem, T., Lora, A. and Giráldez, J.V. 2017. Soil erosion control, plant diversity, and arthropod communities under heterogeneous cover crops in an olive orchard. Environmental Science Pollution Research. DOI 10.1007/s11356-016-8339-9

Henderson, D.W. 1979. Soil Management in SemiArid Environments. "Agriculture in Semi-Arid Environments", Ecological Studies 34. 224-237.

Maetens, W., Poesen, J. and Vanmaercke, M. 2012. How effective are soil conservation techniques in reducing plot runoff and soil loss in Europe and the Mediterranean?. Earth-Science Reviews 115. 21-36.

MAGRAMA 2013. Encuesta sobre superficie y redimiento de los cultivos. Análisis de las técnicas de mantenimiento de los suelos y de los métodos de siembra en España. Madrid, Ministerio de Agricultura, Alimentación y Medio Ambiente (MAGRAMA).

MARÍn, V.J. 2013. Interfaz gráfica para la valoración de las pérdida de suelo en parcelas de olivar. Cordoba, Spain, Universidad de Cordoba.

Montanarella, L. 2007. Trends in Land Degradation in Europe. In Climate and Land Degradation. Environmental Science and Engineering. Eds.: Sivakumar, M.V.K. and Ndiang'ui, N., BerlinHeidelberg, Springer, 583-104. 
Paredes, D., Cayuela, L., Gurr, G.M. and Campos, M. 2015. Is Ground Cover Vegetation an Effective Biological Control Enhancement Strategy against Olive Pests? PLOS One. http://dx.doi.org/10.1371/journal. pone. 0117265

Romero, P., Castro, G., Gómez, J.A. and Fereres, E., 2007. Curve number values for olive orchards under different soil management. Soil Science Society of America Journal 71. 1758-1769.

Ruíz de Castroviejo, J. 1969. Explotación de olivares en asociación con trébol subterráneo. Agricultura 443. Marzo, 135-139.

Ruiz-Colmenero, M., Bienes, R. and Marqués, M.J. 2011. Soil and water conservation dilemmas associated with the use of green cover in steep vineyards. Soil \& Tillage Research 117. 211-223.

Scheidel, A. and Krausmann, F. 2011. Diet, trade and land use: a socio-ecological analysis of the transformation of the olive oil system. Land Use Policy 28. 47-56.

Soriano, M.A., Cabezas, J.M., Ramos, A., Lora, A. and Gómez, J.A. 2016. Characterization of cover crops for use in olive groves and vineyards in certified systems under Mediterranean conditions. AgroEnviron 2016 West Lafayette, IN.
Sweet, R.M. and Schreiner, R.P. 2010. Alleyway Cover Crops Have Little Influence on Pinot noir Grapevines (Vitis vinifera L.) in Two Western Oregon Vineyards. American Journal of Enology and Viticulture 61. 240-252.

Vanwalleghem, T., Amate, J.I., de Molina, M.G., Fernández, D.S. and Gómez, J.A. 2011. Quantifying the effect of historical soil management on soil erosion rates in Mediterranean olive orchards. Agriculture, Ecosystems and Environment 65.341-351.

Vicente-Vicente, J.L. 2017. Soil organic carbon sequestration in olive groves of Andalusia: effect of the managements on soil organic carbon dynamics. PhD Thesis. Jaen, University of Jaen.

Winter, S., Zaller, J.G., Kratschmer, S., Pachinger, B., Strauss, P., Bauer, T., Paredes, D., Gómez, J.A., Guzmán, G., Landa, B., Nicolai, A., Burel, F., Cluzeau, D., Popescu, D., Bunea, C., Ротthoff, M., Guernion, M. and Batáry, P. 2016. How does vineyard management intensity affect ecosystem services and disservices - insights from a meta-analysis. Geophysical Research Abstracts 18, EGU2016-1769, 2. 